\title{
RETOMADA, RECUSA E ESVAZIAMENTO DE IMAGENS MÍTICO-SIMBÓLICAS NA MODERNIDADE: O CISNE DE RALPH GIBSON E DE MARINA COLASANTI
}

\author{
RESUMPTION, REFUSAL AND EMPTINESS OF THE MYTHICAL-SYMBOLIC IMAGES \\ IN THE MODERNITY: THE SWAN OF RALFPH GIBSON AND MARINA COLASANTI \\ Leandro Passos ${ }^{1}$ \\ passosle@yahoo.com.br
}

\begin{abstract}
RESUMO: Este artigo se propõe a analisar de que modo as imagens simbólicas do mito de Zeus e Leda se configuram como elementos do plano de expressão e suscitam novos planos de conteúdo no miniconto da escritora Marina Colasanti, inserido em sua obra Contos de amor rasgados (1986), intitulado "Castor e Pólux, sequer pressentidos", e na fotografia "Após a partida do cisne" (1974) do fotógrafo Ralph Gibson. Para tanto, além de verificar como o mito do cisne é retomado e ressignificado no texto verbal e visual, o presente artigo procurará verificar a peculiaridade estética, portanto poética, de cada texto.
\end{abstract}

PALAVRAS-CHAVE: mito; miniconto; fotografia; metonímia; paródia.

Abstract: This article aims at analysing how the mythical-symbolic images of the myth of Zeus and Leda set themselves up as elements in the level of expression and raise new levels of content in the mini tale of the writer Marina Colasanti, inserted in her work Contos de amor rasgados (1986), with the title "Castor e Pólux sequer pressentidos" and in the photo "Após a partida do cisne" (1974) taken by the photographer Ralph Gibson. For this objective we are going to verify how the myth of the swan is resumed and given a new sense in the verbal and visual text and we are also going to verify the aesthetic peculiarity, therefore poetical, of each text.

KEY WORDS: myth; mini tale; photograph; metonymy; parody.

\section{A particularidade do mito na contemporaneidade}

Uma vez que pretendemos analisar de que modo o mito de Zeus e Leda é retomado no miniconto de Marina Colasanti e na fotografia de Ralph Gibson, faz-se necessário que verifiquemos a natureza de cada texto, quais sejam, o mítico, o "contístico" e o fotográfico.

No mito, Leda é seduzida por Zeus metamorfoseado em cisne. Algumas versões narram a mortal dando à luz dois ovos dos quais nasceram os mortais Castor e Clitemnestra e os imortais Helena e Pólux. Outra, que Zeus transformou-se em cisne, para conquistar Leda, depois que esta, para fugir-lhe, se transformou em gansa. As

\footnotetext{
${ }^{1}$ Universidade Estadual Paulista - UNESP

Instituto de Biociências, Letras e Ciências Exatas - IBILCE

Campus de São José do Rio Preto

Programa de Pós-graduação em Letras - Doutorando (CAPES)
} 
diversas versões ocorrem porque a maioria dos mitos foi recontada e, conseqüentemente, modificada pelos rapsodos, pelos poetas, e pelos mitógrafos.

De acordo com Chevalier (1989), o cisne é um símbolo de grande integração do amor, de nobreza, de elegância e de coragem; a ave liga-se, também, à música e ao canto. Desse modo, nada mais coerente do que o deus supremo do Olimpo metamorfosear-se nesse animal de grande harmonia de estilo.

Távola (1985, p.12), no que se refere à simbologia dos mitos, diz que expressar-se por meios simbólicos "é a forma de as mentes individual e coletiva fazerem emergir ao consciente o que nelas jaz ou lateja em profundidade, oclusão, alcance, memória ancestral ou futura". Para o autor, o homem traz consigo uma espécie de memória da humanidade, uma forma de conservar, no inconsciente, experiências ancestrais da espécie.

Segundo Eliade (1972, p. 10), os mitos se "transformaram e enriqueceram no curso dos séculos, sob a influência de outras culturas superiores ou graças ao gênio de alguns indivíduos excepcionalmente bem dotados". Dessa forma, as narrativas mitológicas formam-se por um processo de "bricolagem", no qual cada povo, com sua respectiva cultura, insere e altera o conteúdo mítico da oralidade. Além disso, foi a partir dos clássicos, tais como Hesíodo, Homero, Virgílio, Ovídio e outros, que passamos a ter essas narrativas mitológicas na forma escrita e literária.

Esses apontamentos entram em consonância com os estudos do antropólogo LéviStrauss (1987), que estudou o pensamento dos antigos para mostrar que os assim chamados selvagens não são atrasados nem primitivos, mas operam com o pensamento mítico. A fim de explicar a composição de um mito, Lévi-Strauss refere-se a bricolage. Um bricoleur produz um objeto novo a partir de pedaços e fragmentos de outros objetos. Vai reunindo, sem um plano muito rígido, tudo o que encontra e que serve para o objeto que está compondo. O antropólogo ressalta, ainda, que o pensamento mítico faz exatamente a mesma coisa, isto é, vai reunindo as experiências, as narrativas, os relatos, até compor um mito geral. Com esses materiais heterogêneos, produz a explicação sobre a origem e a forma das coisas, suas funções e suas finalidades, os poderes divinos sobre a natureza e sobre os homens.

Ginzburg (2001), em Olhos de madeira, dedica um capítulo à discussão acerca da definição de mito, passando pelas análises de Platão, Aristóteles, Santo Agostinho, Abelardo, Maquiavel, e outros. O autor conclui que "o mito é por definição um conto que já foi contado, um conto que já se conhece. Assim, a consciência mítica, embora rejeitada no mundo moderno, ainda está viva e atuante nas civilizações antigas" (p. 84). Portanto, o 
valor e o significado do mito, quando ele se encontra inserido como parte central de uma sociedade, corresponde a um condutor das transformações ocorridas nessa sociedade e, no caso da greco-latina, inserida na mente dos cidadãos que a compõem.

Segundo Moisés (1971, p. 347), "o mito implica uma narrativa e, ipso facto, o concurso da imaginação". Para ele, "criar um mito significa conceber, através das forças imaginativas, uma história que reflete um modo não lógico de enfrentar o mundo". Ele vê uma estreita ligação entre mito e metáfora: "o mito seria uma macrometáfora, espécie de transposição amplificante de uma metáfora-matriz, elaborada a partir de uma analogia elementar, descoberta instintivamente, entre duas entidades ou coisas".

Assim, se o mito foi e ainda é facilmente transmitido por via oral, quer se acredite nele como sagrado quer não, ele é, seguramente, uma "forma simples", no sentido que Jolles (1976) Ihe dá, isto é, cerne de uma narrativa, contido completamente em seu "conteúdo", não importando sua "forma".

Frye (2000, p. 28), por sua vez, observa que mito é "uma concepção que atravessa muitas áreas do pensamento contemporâneo: antropologia, psicologia, religião comparada, sociologia e diversas outras". O autor enfatiza, porém, o que o termo significa em crítica literária hoje, e explica que o mito é e sempre foi um elemento integrante da literatura; o interesse de poetas pela mitologia tem sido notável e constante desde a época de Homero. De acordo com Frye, os escritores interessam-se pelos mitos pela mesma razão pela qual os pintores se interessam por arranjos de naturezas mortas, ou seja, ilustram princípios essenciais de narração. O artista que os usa, então, tem o problema técnico de fazê-los plausíveis ou verossímeis para um público sofisticado. $\mathrm{O}$ mito oferece, portanto, "os principais contornos e circunferência de um universo verbal que é mais tarde também ocupado pela literatura. A literatura é mais flexível que o mito e preenche esse universo de modo mais completo [...]" (FRYE, 2000, p. 41).

É com base nesses contornos e circunferências que nos propomos a analisar o conto "Castor e Pólux, sequer pressentidos", de Marina Colasanti, e a fotografia "após a partido do cisne", de Ralph Gibson, que resgatam, em seus procedimentos de significação, a poética do mito.

Chamamos de poética do mito, pois percebemos, de acordo com os posicionamentos teóricos citados, que o mito tem um modo particular e simbólico de "dizer o mundo"; ele se utiliza dos materiais já existentes para significar. A contista e o fotógrafo, em seus respectivos textos, utilizam os mitos como formas de expressão para sugerir e figurativizar conteúdos; procedimento estilístico e literário que os aproxima da concepção de mito de Roland Barthes (1980, p. 131), ao dizer que "o mito não se define 
pelo objeto de sua mensagem, mas pela maneira como a profere: o mito tem limites formais, mas não substanciais".

\section{A retomada, a recusa e o esvaziamento das imagens míticas no conto de Marina Colasanti}

O título do conto de Marina Colasanti "Castor e Pólux, sequer pressentidos"2 funciona como elemento contextualizador que remete ao mito de Zeus e Leda, fornecendo, portanto, uma primeira orientação. Verificamos um acontecimento semelhante ao mito: um cisne e uma mulher que se relacionam.

O início da narrativa inicia-se com uma pergunta que insere o leitor, não num acontecimento mítico, mas inusitado, qual seja, a entrada de um cisne "em estardalhaço de asas e penas". Se no mito essa relação de elegância é coerente para a metamorfose de Zeus, no miniconto a vinculação é invertida.

O cisne de Marina Colasanti perde a elegância e se configura num amante, inicialmente, desajeitado: "perdida a elegância com que deslizaria sobre a água"; "equilíbrio ao precário avanço". Convém ressaltar, que a ave oscila entre o amante desastrado, "ondeando o corpo de um lado para o outro, enquanto o pescoço chicoteava o ar [...]", e o amante hábil, "O pescoço, esse sim, seduzia."; "[...] as asas abertas roçando o corpo da mulher, o pescoço macio envolvendo-lhe os ombros, deslizando pela nuca, o bico atrevido procurando seu ponto mais sensível atrás da orelha" (grifos nossos).

Essa oscilação, desastroso versus habilidoso, configura-se nas características do amante que ora são humanas, percebidas no próprio ato sexual sugerido entre o cisne e a mulher; ora são de animal, "as marcas enlameadas nos lençóis, as plumas espalhadas entre as dobras dos panos [...], o cheiro do ninho"; "Duas vezes a enganara o palmípede".

O amante é descrito, no conto, pelo substantivo "cisne" (hipônimo); pelos pronomes pessoais reto "ele" e oblíquo átono "o", "se ele voltasse, não o receberia"; pelos adjetivos "visitante" e "palmípede" (hiperônimo). A pluralidade lingüística e gramatical do plano de expressão para figurativizar o amante pode se ligar à diversidade do tipo de parceiro masculino que procura a mulher apenas para uma noite de prazer e que vai embora na manhã seguinte (plano de conteúdo).

Afora esses recursos estilísticos, portanto estéticos, o pescoço, metonímia do cisne-amante e, particularmente, de seu falo, reforçam a quebra da simbologia mítica, ou melhor, afastam as imagens simbólicas coerentes para o período "clássico" no qual o mito

\footnotetext{
${ }^{2}$ Anexo
} 
era acreditado e ritualizado. O cisne com seu pescoço "Longo, flexível, voluptuosamente sinuoso, de um branco tão igual e brilhante", metonimicamente, torna-se um falo que, com seu bico atrevido, "mais parecia um um jorro de leite", procurava o ponto mais sensível da mulher. Vale salientar que "jorro de leite" sugere a atmosfera erótica do sêmen. Assim, o cisne mítico é retomado no conto de Marina Colasanti mais por sua forma icônica pescoço-falo do que por sua simbologia mítica, apontada por Chevalier (1989).

O conto, podemos dizer, esvazia os conteúdos míticos e os insere no cotidiano dos relacionamentos amorosos. O mito, como nos aponta Roland Barthes (1980), serve, para o conto, como plano de expressão para figurativizar o plano de conteúdo, a saber, o drama da mulher e de seu visitante inusitado.

Nesse sentido, a forma narrativa conto torna-se coerente para veicular os sentidos nele presentes. A estrutura concisa e breve do relato contribui para a singularização da rapidez do relacionamento dos amantes.

Para Poe (apud GOTLIB, p. 34-5), a elaboração do conto é produto de um extremo domínio do autor sobre os seus materiais narrativos; é produto, também, de um trabalho consciente, que se faz por etapas, cujo objetivo é causar o efeito único, ou impressão total. Sob a economia dos meios narrativos, deve, o contista, conseguir o máximo de efeitos.

Ainda de acordo com as observações de Poe, o contista condensa a matéria para apresentar os seus melhores momentos. Assim, a questão da brevidade é o elemento caracterizador do conto, ao qual é necessário causar o efeito, impressão total, no leitor, que deve sempre ser mantido em suspense. O conto constitui uma unidade/célula dramática; contém, portanto, um só conflito, um só drama, uma só ação. Todos os ingredientes do conto levam a um mesmo objetivo, convergem para o mesmo ponto; essa unicidade está relacionada à concentração de efeitos e de pormenores: o conto dispensa as digressões, as divagações, e os excessos; exige, pois, que todos os seus componentes estejam condensados, que apontem para uma única direção e que circulem ao redor de um só drama.

O lugar geográfico por onde as personagens circulam é sempre de âmbito restrito: um bairro de uma cidade, uma rua de um bairro, uma casa de uma determinada rua e, mesmo, um quarto de dormir ou uma sala de estar de uma determinada casa bastam para que se desenvolva o enredo. Cabe aqui um comentário importante de Moisés (1971, p.126) sobre as questões de espaço do gênero conto:

Raramente as personagens se deslocam para outros sítios. E quando isso ocorre, de duas uma: ou a narrativa 'procura' abandonar sua condição de 
conto, ou o deslocamento advém de uma necessidade imposta pelo conflito que the serve de base, vale dizer, preparação da cena, busca de pormenores enriquecedores da ação, etc.

Essas características apontadas por Moisés podem ser encontradas no conto, tendo em vista que a ação ocorreu no quarto da personagem. Aliás, esse espaço é pressuposto por meio das expressões "janela adentro", "sobre a cama", "travesseiro", "a cama revirada [...] nos lençóis" e "cabeceira da cama".

À noção de espaço, segue-se a de tempo: os acontecimentos narrados no conto podem dar-se em curto lapso de tempo, uma vez que não interessam o passado e o futuro, as coisas se passam em horas, ou dias. Em "Castor e Pólux, sequer pressentidos", o cisne chega no "meio da noite" e parte "ao alvorecer", e, "à medida que a luz da manhã" avança, "no calor do dia", mais forte se fazia o cheiro do ninho, concomitantemente com a solidão da mulher.

Entre o sexto parágrafo, em que a mulher se descobre grávida, e o sétimo, há um espaço marcado por uma linha vazia, o que graficamente parece sugerir o tempo decorrido de uma gestação, recurso dir-se-ia iconográfico muito econômico e bem adequado ao gênero conto, sobretudo característico para o praticado por Colasanti.

Quanto à questão do número de personagens, Moisés (1971, p. 127) informa, também, que "poucas são as personagens no conto, como decorrência natural das características apontadas: as unidades de ação, espaço e tempo só podem estabelecerse com reduzida população no palco dos acontecimentos". No conto analisado, temos apenas mulher, cisne e uma referência aos criados no último parágrafo.

Ainda dentre as considerações de Moisés, em conseqüência das unidades que governam a estrutura do conto, "as personagens tendem a ser estáticas ou planas, porque as mesmas são surpreendidas no instante climático de sua existência, o contista as imobiliza no tempo, no espaço e na personalidade" (p.128). Diferente das personagens do romance, que crescem diante da narrativa, as do conto oferecem somente uma faceta de seu caráter.

Como já dito, a estrutura do conto e seu modo de significação, plano de expressão, se homologam com o plano de conteúdo da narrativa: o drama do relacionamento amoroso dos amante - mulher e cisne.

Feitas essas considerações acerca das referências simbólicas do mito de Zeus e Leda no conto de Marina Colasanti, podemos, neste momento, verificar de que modo esses conteúdos são "ressignificados" na fotografia de Ralph Gibson. Convém lembrar que a linguagem verbal do miniconto organiza-se com base na linguagem articulada que 
compõe a língua. A não-verbal da fotografia vale-se das imagens sensoriais várias, tais como as visuais com suas cores e formas.

\section{A singularização do mito na imagem fotográfica}

O fotógrafo Ralph Gibson, em seus mais de quarenta anos de carreira, ganhou quinze prêmios internacionais e foi condecorado Commandeur l'Ordre des Arts et des Lettres da Françae, doutor honorário da University of Maryland e da Ohio Wesleyan University. Iniciou a arte fotografando sob os ensinamentos de uma mestre da fotografia, Dorothea Lange e, em seguida, com Robert Frank. Com Lange e Frank, aprendeu o rigor da técnica, a luz perfeita, o enquadramento detalhado, mas como todo bom aluno, superou seus mestres.

Tem mais de 30 livros publicados, dentre os quais o Libris ex, resultado de uma pesquisa e documentação fotográfica do aspecto visual da escrita em suas várias formas. Gibson tem verdadeiro fascínio por livros e adora escrever. Já fez mais de 35 monografias, a mais atual Light Strings, publicada em 2004.

Suas fotografias estão incluídas em mais de cento e cinqüenta coleções em museus pelo mundo e apareceram em centenas de exposições. Seu estilo particular já foi várias vezes apontado por críticos como cruzamento das tendências surrealista e minimalista. Por esse estilo, nada mais natural do que a referência mítica ressignificada em sua fotografia "Woman with feather"3, cujo títlo em português é "Após a partida do cisne", de 1974.

No texto fotográfico de Gibson, olhamos para um "fragmento" de um corpo feminino, envolvido por um tecido branco, recurso plástico que nos lembra as asas de um pássaro. A perna direita está flexionada e apoiada pela mão esquerda, e a perna esquerda está estendida. Com a mão direita, a mulher da imagem segura uma pena branca e preta. Por essa posição, o corpo da figura fica levemente contorcido, e o tronco se vira para o leitor da fotografia. É interessante notar que as nádegas também ficam de frente para o espectador, o que potencializa a sugestão de introdução da pena nas partes íntimas da mulher.

Assim como no conto de Colasanti, o aspecto metonímico se faz presente, gerando o aspecto erótico do texto visual fotográfico. A "pena-falo" figurativiza o possível amante da figura, ou melhor, singuraliza, metonimicamente, o falo, que, de acordo com o flagrante da câmara, está prestes a penetrar.

\footnotetext{
${ }^{3}$ Museum Purchase: Charina Foundation Purchase Fund, $46.1 \times 30.7 \mathrm{~cm}$.
} 
Tendo em vista que a imagem fotográfica é o instante retido no espaço e tempo, e um recorte de um todo, a própria fotografia se faz metonimia de um ato sexual, de um relacionamento amoroso. Se no conto, com sua linguagem verbal, lemos um conciso e breve acontecimento, na fotografia, com sua linguagem visual, vemos um pequeno traço de um "quase coito". Esse termo é denominado aqui porque a captação dos referentes pela objetiva se deu antes da introdução plena da pena, agora signo motivado de sugestão estética e erótica.

De acordo com Dubois (1994), se um dado objeto é captado num determinado momento e num determinado tempo, esse ato fotográfico se torna único, pois remete, apenas, a um referente, ao "seu", ao mesmo que o causou. Assim, o traço (fotográfico) só pode ser, em seu fundo, singular, tão singular quanto seu próprio referente.

Esses apontamentos ligam-se às elucidações de Roland Barthes (1984), ao dizer que o fotografia reproduz ao infinito só ocorre uma vez: ela repete mecanicamente o que nunca mais poderá repetir-se existencialmente. É o "eternizar" o momento flagrado, o "congelar", o "imobilizar".

A captação do objeto no espaço e tempo determinados não pode repetir-se. A imagem resultado desse "instante único retido" jamais poderá ser apreendida do mesmo modo, jamais será exatamente igual. A mesma imagem só poderá ser reproduzida a partir do negativo de origem.

As cópias em positivo são de fato apenas de fotos, 'metafotos', imagens em segundo grau, que testemunham simplesmente que em fotografia não existe reprodução ou re-produção. A fotografia como tal, captada em seu princípio - a impressão, o negativo, a foto polaróide, o daguerreótipo etc. é sempre necessariamente singular (DUBOIS, 1994, p. 73).

A imagem fotográfica não é somente uma impressão luminosa; é além disso, uma impressão trabalhada por um gesto radical que a faz por inteiro de uma vez só; o gesto do corte, do "cut", que faz seus golpes recaírem ao mesmo tempo sobre o fio da duração e sobre o contínuo da extensão.

De acordo com Dubois, no que se refere ao tempo, "a imagem-ato fotográfica interrompe, detém, fixa, imobiliza, destaca, separa a duração, captando dela um único instante" (p. 161). O ato "corta", o obturador "guilhotina" a duração, instala uma espécie de fora-do-tempo; reduz o fio do tempo, o instante detido; esse lapso "curto" e "único" retirado do "contínuo do tempo referencial" torna-se perpétuo e "eternizado", destinado a durar no próprio estado em que foi captado e cortado (p. 163).

No que diz respeito ao espaço, do mesmo modo, a "imagem-ato" fraciona, levanta, 
isola, capta, recorta uma porção de extensão. Assim, a foto aparece como uma "fatia" única e singular de espaço-tempo, literalmente cortada ao vivo; marca tomada de empréstimo, subtraída de uma continuidade dupla. Pequeno bloco de "estando-lá", pequena comoção de "aqui-agora", furtada de um duplo infinito (p. 161).

O gesto do fotógrafo consiste em "subtrair" de uma vez todo espaço de um contínuo, "arranca" de um só golpe o que o difere do pintor que compõe e preenche a tela aos poucos:

Cada objetivo, cada tomada é inelutavelmente uma machadada (golpe de machado) que retém um plano do real e exclui, rejeita, renega a ambiência [...] Sem sombra de dúvida, toda a violência desse gesto do cut. Ele é irremediável. É ele e só ele que determina a imagem, toda a imagem como todo. Espaço literalmente talhado de uma vez e ao vivo pelo ato fotográfico, haja ou não encenação, tudo acontece por inteiro de uma só vez. Em sua condição de princípio, esse é de fato o golpe do corte. (DUBOIS, 1994, p. 178).

Logo, para o autor, a fotografia retém, simultaneamente, espaço e tempo. O ato fotográfico realiza, além do "gesto de corte" na continuidade de um real, uma "passagem", uma "transferência": faz passar de um tempo evolutivo a um tempo petrificado, do instante à perpetuação, do movimento à imobilidade.

O fundamental, de acordo com Dubois, é que, ao "recortar" do mundo um pedaço de espaço e "congelar" o tempo, o ato fotográfico faz deles um "mundo novo" (espaço representado), cuja organização interna se configura a partir da própria forma gerada pelo recorte. "O espaço de representação é, portanto, o operador principal do ato fotográfico (tanto na produção quanto na recepção). É através dele que tudo passa (para a imagem)" (p. 210)

Nesse sentido, se a fotografia é um instante retido no espaço e tempo, podemos dizer que o texto visual de Gibson é eufórico se comparado à disforia do texto de Colasanti. No miniconto, a personagem, além de sentir-se abandonada e enganada pelo "palmípede", frustra-se com o "ovo espúrio"; na fotografia, é a própria figura feminina que manipula a "pena-falo", atitude que se eterniza pelo procedimento particular de construção de sentido da fotografia. É como se a sugestão de início de penetração perdurasse com a imagem retida, como nos explicou Dubois (1994). Desse modo, a euforia se "congela" no espaço e tempo da fotografia, e a disforia se perpetua a cada nova leitura da escrita do miniconto.

Cabem aqui as elucidações de Dias (2005), sobre o diálogo entre literatura e mito: 
[...] é preciso deslocar essa permanência, ou melhor, desequilibrar a moldura que cerca o mito, o que só pode se fazer por um olhar transgressor e criativo. Aí, sim, as relações entre mito e literatura podem ganhar conotações insuspeitadas. O que importa perceber, nesse caso, é o tratamento singularizado dado aos mitos por uma linguagem narrativa que os recria, em seus procedimentos de construção, para gerar novos significados. Por outras palavras, para a consciência moderna o resgate do mito, por via ficcional ou crítica, só pode se fazer se souber transformá-lo em uma realidade móvel, colocando passado e presente em uma contínua circulação de trocas.

Baseado nesses posicionamentos, é possível afirmar que a simbologia mítica presente tanto no miniconto como na fotografia é "reinterpretada" no sentido profano; ocorre uma "continua circulação de trocas", como destaca Dias (2005). Não se trata mais da permanência de significado, mas, sim, de um recurso figurativo inserido no cotidiano de relacionamento amoroso. É por isso, pois, que foi necessário fazer uma "leitura especialmente cuidadosa", a fim de identificar os possíveis sentidos velados no conto e na fotografia.

Aproveitando o que diz João Alexandre Barbosa (1990) acerca de experiência da leitura, o que se lê é o "intervalo", espaço construtivo em que são segregados os sentidos e se estabelece a articulação entre a realidade de fora e a de dentro do texto:

[...] uma leitura intervalar é, a meu ver, capaz de melhor se aproximar da obra, deixando-a melhor revelar os seus elementos estruturadores e, ao mesmo tempo, obrigando o leitor a considerar sem preconceitos, todos aqueles elementos - os históricos, os sociais, os antropológicos, os psicológicos -que convergem para a sua manifestação e que são articulados num espaço/tempo específico de invenção pessoal que é a obra que se lê que, por isso mesmo, não pode desprezar, ou deixar de lado como sabida, a tradição de outras obras e outras leituras (BARBOSA, 2004, p. 44).

Os textos analisados, dialogando direta ou indiretamente com o mito de Zeus e Leda, retomaram, recusaram e esvaziaram os sentidos simbólicos e deram-lhe outro tratamento, estabelecendo, desse modo, as próprias estruturas de significação. Aliás, essa é a essência do recurso dos artistas - contista e fotógrafo: "o trabalho de assimilação e de transformação que caracteriza todo e qualquer processo intertextual" (JENNY, 1979, p. 10).

De acordo com Jenny (1979, p. 22) é necessário que o texto retomado "admita a renúncia à sua transitividade: ele já não fala, é falado. Deixa de denotar, para conotar”. A narrativa mitológica tornou-se significante para sugerir significados nos textos analisados.

Ao esvaziar os conteúdos simbólicos, vale dizer, não ocorre a sua "desconstrução", 
apenas a retomada com diferença, procedimento típico do discurso paródico. Na paródia, mesclam-se e encontram-se vários discursos, por isso, ela pode ser definida como um "jogo de ir e vir", em que o leitor se depara com um discurso polifônico e tem de estabelecer paralelos entre as várias vozes presentes no texto. Assim, o "codificador e, depois, o descodificador, têm de efetuar uma sobreposição estrutural de texto que incorpore o antigo e o novo" (HUTCHEON, 1989, p. 50).

Esse mecanismo ficcional utilizado pelos artistas entra em consonância com as observações de João Alexandre Barbosa, acerca das ilusões da modernidade na poesia. Embora o crítico discuta a linguagem da poesia e a sua relação com o leitor, pode-se dizer que, assim como o poeta moderno, que se interessa pela tradição, uma vez que sua "tradução" em linguagem moderna "implica no desbravamento de novas possibilidades de utilização da linguagem da poesia" (p. 29), Marina Colasanti e Ralph Gibson "transubstanciam" esses conteúdos da tradição mítico clássica. Os artistas, se se pensar nos procedimentos elucidados por Barbosa (1986), "traduzem" a "tradição", na medida em que seus textos perseguem uma convergência de textos possíveis: "a tradução é a via de acesso mais interior ao próprio miolo da tradição" (p.29).

Pela "tradução", a "tradição" do novo perde o seu tom repetitivo, o que se consegue obter por meio de uma linguagem e recursos estéticos criativos. O que em nosso artigo chamamos de "retomada", "recusa" e "esvaziamento" é justamente a leitura de acréscimo, na qual ler o miniconto e a fotografia (textos novos) na mitologia clássica (textos antigos) significar (re)novar.

\section{Referências}

BARBOSA, J. A. As ilusões da modernidade. In: As ilusões da modernidade: notas sobre a historicidade da lírica moderna. São Paulo: Perspectiva, 1986 (Debates, 196). p. $13-37$.

. A leitura do intervalo. São Paulo: lluminuras, 1990.

47, 2004.

A. Reflexões sobre o método. Revista Mosaico. S. J. do Rio Preto, v. 3, p. 31-

BARTHES, R. Mitologias. São Paulo: Difel, 1980.

A Câmara clara. Trad. de Júlio Castañon Guimarães. Rio de Janeiro: Nova

Fronteira, 1984.

COLASANTI, M. Contos de amor rasgados. Rio de Janeiro: 1986.

CHEVALIER, J. GHEERBRANT, A. Dicionário de símbolos. Mitos, sonhos, costumes, gestos, formas, figuras, cores, números. Rio de Janeiro: José Olympio, 1989.

DIAS, M. H. M. A presença de elementos míticos na narrativa de Teolinda Gersão.

Disponível em:

<http://www.teolindagersao.com/art_dias_maria_heloisa.htm;http://www.hottopos.com/not and7/heloisa.htm>. Acesso em 15 mar. 2005.

DUBOIS, P. O ato fotográfico e outros ensaios. Campinas: Papirus, 1994. 
ELIADE, M. Mito e realidade. São Paulo: Perspectiva, 1972

FRYE, N. Fábulas de identidade. São Paulo: Nova Alexandria, 2000.

GINZBURG, C. Olhos de madeira. - Nove reflexões sobre a distância. São Paulo: Cia. das Letras, 2001.

HUTCHEON, L. Uma teoria da paródia. (Trad. Teresa L. Perez). Lisboa: Ed. 70, 1989. JENNY, L. A estratégia da forma. In: Poétique: revista de teoria e análise literárias. Intertextualidades. (Trad. C.C. Rocha). Coimbra: Livraria Almedina, 1979.

JOLLES, A. Formas simples: legenda, saga, mito, adivinha, ditado, caso, memorável, conto, chiste. São Paulo: Cultrix, 1976.

LEVI-STRAUSS, S. Antropologia estrutural. Rio de Janeiro: Tempo Brasileiro, 1987. MOISÉS, M. Dicionário de termos literários. São Paulo: Cultrix, 1971.

TÁVOLA, A. Comunicação é mito: televisão e leitura crítica. Rio de Janeiro: Nova Fronteira, 1985. 


\section{Anexo 1}

\section{Castor e Pólux, sequer pressentidos}

Que cisne era aquele que no meio da noite, sem quê nem porquê, irrompia pela sua janela adentro, em estardalhaço de asas e penas?

Aterrissando sobre o tapete, perdida a elegância com que deslizaria sobre a água, avançava com as patas espalmadas, ondeando o corpo de um lado para o outro, enquanto o longo pescoço chicoteava o ar para garantir algum equilíbrio ao precário avanço.

O pescoço, esse sim, seduzia. Longo, flexível, voluptuosamente sinuoso, de um branco tão igual e brilhante, mais parecia um jorro de leite desenhando arabescos na escuridão. E já pulava o cisne sobre a cama, as asas abertas roçando o corpo da mulher, o pescoço macio envolvendo-lhe os ombros, deslizando pela nuca, o bico atrevido procurando seu ponto mais sensível atrás da orelha.

Ao alvorecer partiu o cisne, deixando a mulher em doce lassidão. Transformada porém em desagrado crescente, à medida que a luz da manhã, fazendo mais clara, evidenciava a cama revirada, as marcas enlameadas nos lençóis, as plumas espalhadas entre as dobras dos panos, e mais forte se fazia, no calor do dia, o cheiro de ninho.

Não, se ele voltasse, não o receberia; decretou a mulher lamentando sua condescendência na noite anterior.

Mas o cisne não veio naquela noite, nem na seguinte, nem na outra ainda. E ela estava quase começando a crer que tudo não passara de uma alucinação, quando percebeu que o visitante deixara outras marcas. Alargava-se-Ihe a cintura, cediam as cadeiras, e um peso lhe alertava o ventre.

Chegando enfim o dia aprazado, deitou-se. Abriu as pernas. Mordeu um travesseiro, agarrou-se à cabeceira da cama. Expulsou. Mas nenhum choro coroou seu esforço. No vértice se suas coxas não havia vestígio de sangue. Nenhuma criança. Somente, cândido e enigmático, jazia um enorme ovo.

Duas vezes a enganara o palmípede. Nem mais viera vê-la. Nem Ihe fizera um filho de verdade. Tomada de ódio e repugnância chamou os criados, mandou que levassem aquele ovo espúrio. E longe dos seus olhos o destruíssem, jogando no lixo seus resíduos. 
Anexo 2

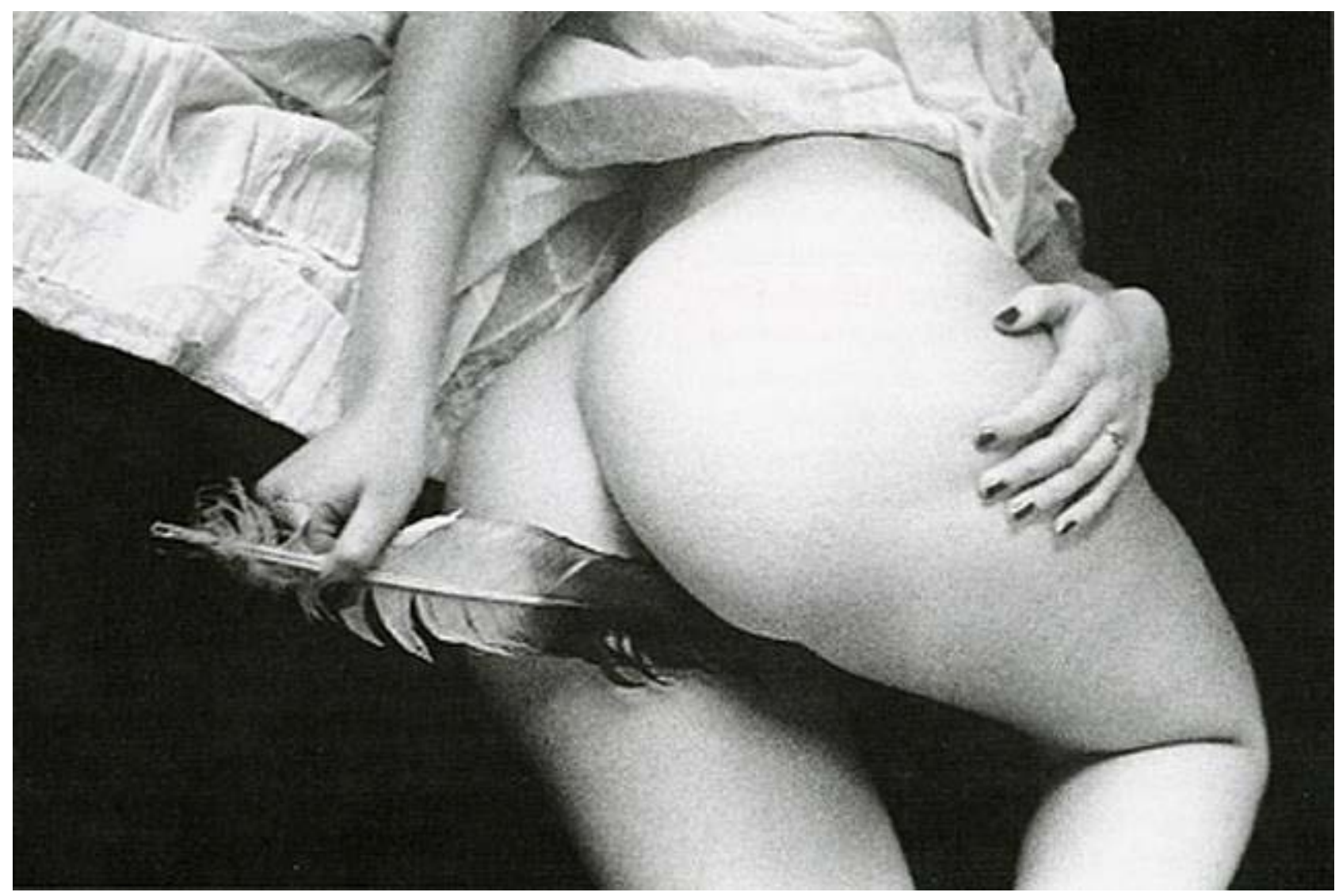

